\title{
An efficient strategy for generation of transgenic mice by lentiviral transduction of male germline stem cells in vivo
}

Jinzhou Qin, Haixia Xu, Pengfei Zhang, Conghui Zhang, Zhendong Zhu, Rongfeng Qu, Yuwei Qin and Wenxian Zeng ${ }^{*}$

\begin{abstract}
Background: Male germline stem cells (MGSCs) are a subpopulation of germ cells in the testis tissue. MGSCs are capable of differentiation into spermatozoa and thus are perfect targets for genomic manipulation to generate transgenic animals.

Method: The present study was to optimize a protocol of production of transgenic mice through transduction of MGSCs in vivo using lentiviral-based vectors. The recombinant lentiviral vectors with either EF-1 or CMV promoter to drive the expression of enhanced green fluorescent protein (eGFP) transgene were injected into seminiferous tubules or inter-tubular space of 7-day-old and 28-day-old mouse testes. At 5 or 6 wk post-surgery, these pre-founders were mated with wild-type C57BL/6J female mice (1.5 to 2.0-month-old).

Results: Sixty-seven percent of F1 generation and $55.56 \%$ of F2 offspring were positive for eGFP transgene under the control of EF-1 promoter via PCR analysis. The transgenic pups were generated in an injection site-and age-independent manner. The expression of transgene was displayed in the progeny derived from lentiviral vector containing CMV promoter to drive transgene, but it was silenced or undetectable in the offspring derived from lentiviral vector with transgene under EF-1 promoter. The methylation level of gDNA in the promoter region of transgene was much higher in the samples derived lentiviral vectors with EF-1 promoter than that with CMV promoter, suggesting eGFP transgene was suppressed by DNA methylation in vivo.

Conclusion: This research reported here an effective strategy for generation of transgenic mice through transduction of MGSCs in vivo using lentivirus vectors with specific promoters, and the transgenic offspring were obtained in an injection site-and age-independent manner. This protocol could be applied to other animal species, leading to advancement of animal transgenesis in agricultural and biomedical fields.
\end{abstract}

Keywords: In vivo, Lentivirus vectors, Male germline stem cells, Transgenesis

\section{Background}

Transgenic animals have been widely used in biomedical, agricultural and veterinary research. There has been increasing interest in developing approaches to modify genome for transgenesis. The techniques, such as pronuclear DNA microinjection [1], embryo stem cell based genome manipulation [2-4], combination of gene modification with nuclear transfer $[5,6]$ DNA transposon-mediated approaches by microinjection

\footnotetext{
* Correspondence: zengwenxian2015@126.com

College of Animal Science and Technology, Northwest A\&F University, No. 22

Xinong Road, Yangling, Shaanxi 712100, China
}

[7], and the gene targeting tools (zinc finger nucleases and TALENs, $[8,9]$ ) have been applied for generating transgenic animals. However, these approaches are complicated, time-consuming, and high cost as well. In recent years, CRISPR-Cas9 system has been widely used for transgenic animals, however it may cause offtarget effects in vivo [10]. The novel CRISPR/Cpf1 system was efficient for genome-editing in human cells, but has not been used for generating of transgenic animals [11]. Therefore, a simple strategy of transgenesis is highly desirable. 
Mammalian spermatogenesis is a continuous, complex process by which spermatogonia proceed through mitosis, meiosis and cytological transformations resulting in formation of numerous spermatozoa throughout the adult life of a male [12]. This spermatogenic process is relied on a subpopulation of germ cells, which are capable of self-renewal and differentiation to spermatozoa, thereby giving rise to the entire spermatogenic lineage. These male germline stem cells (MGSCs) are the only cells in the adult male body that pass the genetic information on to the next generation, making them attractive targets for genetic manipulation [13, 14].

MGSCs based gene modification has comparative advantage over zygote- or oocyte- mediated transgenesis which requires large number of females for super ovulation and expertise for embryo manipulation [15]. Recently, Sahagal and his colleagues [16] reported that manipulation of germ cells through injection of lentiviruses into testis tissue led to generation of transgenic pups with overall success rate as high as $60 \%$, moreover, the transgene was heritable. Although expression of eGFP was detected under confocal microscopy in multiple tissues of transgenic pups, image of the pups with GFP fluorescence was not presented in their article. The objective of the present study was to simplify and optimize the approach for generating of genome modified mice via lentivirus transduction in vivo. Injection of lentivirus into mouse testis tissue resulted in integration of transgene into host genome in an injection site- and age-independent manner. Expression of eGFP transgene was detected in the offspring derived via injection of lentiviral vectors containing eGFP under cytomegalovirus (CMV) promoter, indicating that lentiviral transduction of MGSCs in vivo is a simple, efficient, low laborintensive approach to produce transgenic mice.

\section{Methods}

\section{Experimental design}

Experiment 1 was to optimize the protocol for generation of transgenic mice by lentiviral transduction of male germline stem cells. The effects of injection sites and age of pre-founder mouse was to be elucidated. Experiment 2 was to detect the effect of the promoter for driving the expression of the transgene.

\section{Animals}

C57BL/6J male mice (aged $7 \mathrm{~d}$ and $28 \mathrm{~d}$ ) and C57BL/6J female mice (aged 1.5 to $2 \mathrm{mo}$.) were obtained from the Fourth Military Medicine University (Xi'an, China). All mice were supplied with water and chow ad libitum, housed and bred in a sterile environment with the controlled temperature $\left(25 \pm 5{ }^{\circ} \mathrm{C}\right)$ and humidity (30-70 \%), and $14 \mathrm{~h}$ night a day. The day of birth was designated as $\mathrm{d}$ 0. All protocols for the experiments were approved by and performed under the guidance of the Institutional Animal Care and Use Committee of the Northwest A\&F University. All the treatments were carried out in accordance with relevant guidelines and regulations.

\section{Viral vectors}

Lentiviral vectors as a type of retrovirus that can infect both dividing and non-dividing cells were widely used for introduce transgenes or gene knockdown. The nondividing or terminally differentiated cells such as neurons, macrophages, hematopoietic stem cells, retinal photoreceptors, and muscle and liver cells can be transduced by lentiviral vectors [17]. The lentiviral vectors containing cytomegalovirus (CMV) or human elongation factor-1 (EF-1) promoters to drive eGFP expression were used in this study. The CMV promoter is a widely used promoter and EF-1 is a constitutive promoter of human origin. The lentivirus with EF-1 promoter driving eGFP was packaged in our lab based on the previous protocols [18], and the lentivirus with CMV promoter driving eGFP was a gift from Dr. Wuzi Dong (College of Animal Science and Technology, Northwest A \& F University).

\section{Injection of lentiviral particles and generation of transgenic mice}

In Experiment 1, to test age effect of pre-founder, sixteen male mice aged $7 \mathrm{~d}$ (body weight $4 \pm 1 \mathrm{~g}$ ) were randomly allocated to two groups, named A and B. And sixteen males aged $28 \mathrm{~d}$ (body weight $14 \pm 3 \mathrm{~g}$ ) were randomly allocated to another two groups, named C and D group.

The 7-day-old mice were anaesthetized by intraperitoneal injections of Avertin $(400 \mu \mathrm{L} / 30 \mathrm{~g}$ body weight). An incision of approximate $0.3-0.5 \mathrm{~cm}$ in length was made in skin and muscle anterior to the penis with a sterile ophthalmology scissors. With the help of a sterile dressing forceps, the testes were moved out from the enterocoelia or scrotal sac gently and the dorsal fat pad was pulled for easy operation. To elucidate an effect of injection site, the lentivirus particles were re-suspended in PBS buffer (Life Technology) with trypan blue (0.04 \%). For Group $\mathrm{A} / \mathrm{C}$, lentivirus was injected directly into inter-seminiferous tubular space using a syringe with a needle. For Group B/D, lentivirus was injected into seminiferous tubules via efferent ducts or rete testis under a stereoscopic microscopy as described by Shirohana [19]. The pre-founders were implemented artificial feeding for at least $1 \mathrm{wk}$, then were fed by a maternal mouse for 2 wk followed by self-help feeding. At 6 wk after injection, these pre-founder mice were mated with wild type females of the same strain (aged 1.5-2 mo). 
The 28-day-old mice were injected with a higher dose of Avertin ( $500 \mu \mathrm{L} / 30 \mathrm{~g}$ body weight) by intraperitoneal, the inguinal area hairs were removed and iodine was used for clean and disinfectant. In an effort to avoid injury to the penis, a wound from skin to muscle anterior to the penis of approximate $0.5-1.0 \mathrm{~cm}$ length was cut on a sterile bench. Lentivirus was injected as described above.

Five microlitters of the lentiviral particles at the concentration of $5.5 \times 10^{6} \mathrm{TU} / \mathrm{mL}$ were used in each injected injection in of this study for 7-day-old mice, and ten microlitters of the lentiviral particles for older ones. All the pre-funders were named 0001, 0002 and so on. In Experiment 2, based on the results of Experiment $1,10 \mu \mathrm{L}$ of lentiviral vectors $\left(5.5 \times 10^{6} \mathrm{TU} / \mathrm{mL}\right)$ were injected into inter-tubular space of a C57BL/6 J male mice (aged $28 \mathrm{~d}, n=3$ ). At $5 \mathrm{wk}$ after injection, these pre-founder mice were mated with wild type females of the same strain (aged 1.5-2 mo).

\section{Genotyping}

At 5 or 6 wk post-surgery, the pre-founder male mice were mated with mature wild-type female mice. At $4 \mathrm{wk}$ post-coitum, the new pups of F1 generation were genotyped by PCR in Experiment 1. The eGFP specific primers (Table 2) were used for genotyping. Only those pups with eGFP specific band were considered as transgenic F1 and were named as 1001, 1002 and so on. In order to test whether the transgene could pass to the next generation, half of $\mathrm{F} 1$ generation was mated with each other, and the other half was mated with wild-type for F2 generation. The F2 generation pups were named 2001, 2002 and so on.

\section{Isolation of Genomic DNA (gDNA)}

The tail tips (approximately $0.5 \mathrm{~cm}$ in length) from $\mathrm{F} 1$ and F2 pups and testis tissue from pre-founders were collected for DNA extraction. Samples were cut into small pieces and lysed for $16 \mathrm{~h}$ at $55{ }^{\circ} \mathrm{C}$ in a high salt digestion buffer containing $50 \mathrm{mmol} / \mathrm{L}$ Tris $\cdot \mathrm{HCl}, 1 \%$ SDS, $100 \mathrm{mmol} / \mathrm{L} \mathrm{NaCl}, 100 \mathrm{mmol} / \mathrm{L}$ EDTA and $1,200 \mu \mathrm{g} / \mathrm{mL}$ Proteinase K (Tiangeng, China). The lysate was processed for extraction of DNA based on saltingout methods as described [19].

\section{Polymerase Chain Reactions (PCR) and Reverse Transcriptase Polymerase Chain Reaction (RT-PCR)}

Ubiquitous gapdh gene was amplified as a loading control. The pCD513B-CMV-MCS-EF1 plasmid DNA was introduced as a positive control while the genomic DNA obtained from wild-type mice as a negative control. RNA was isolated from transgenic F1 and F2 animals with TRIZOL (Life Technology, USA) and reverse transcribed (RT) to cDNA with Superscript III RT First
Strand cDNA synthesis Kit (Invitrogen, USA) according to the manufacturer's protocol. PCR was performed in duplicate in a $20 \mu \mathrm{L}$ of reaction volume consisting of TaKaRa Ex Taq (TAKARA, Japan), $0.5 \mu \mathrm{mol} / \mathrm{L}$ of each primer and 500 ng of gDNA or cDNA. The PCR protocol included one cycle at $94{ }^{\circ} \mathrm{C}$ for $10 \mathrm{~min}, 32$ cycles of denaturation at $95{ }^{\circ} \mathrm{C}$ for $15 \mathrm{~s}$, annealing at $60{ }^{\circ} \mathrm{C}$ for $30 \mathrm{~s}$ and extension at $72{ }^{\circ} \mathrm{C}$ for $30 \mathrm{~s}$, then followed final extension for $10 \mathrm{~min}$ at $72{ }^{\circ} \mathrm{C}$. The PCR products were visualized after $2 \%$-agarose gel electrophoresis stained with ethidium bromide (Sigma-Aldrich, USA).

\section{Western blot}

Proteins of the interest tissues (heart, skin, liver, muscle and testis) were isolated from transgenic mice that were confirmed by RT-PCR (non-transgenic pups as negative control). The protein concentration was determined using a Quick Start ${ }^{\text {tw }}$ Bradford Protein Assay Kit (Bio-Rad, USA). Protein complexes were separated by SDS-PAGE, and transferred to nitrocellulose membranes (Hybond ECL, USA). Membranes were probed using the following primary antibodies: anti- $\beta$-actin (Abcom, 1: 1,000), antiGFP (Abcom, 1: 1,000). Secondary antibodies were horseradish peroxidase-linked anti-rabbit antibody (Santa Cruz, 1: 2,000). Protein bands were visualized on a Bio-Rad Chemidoc XRS using a Western Bright ECL Kit (Advansta, Menlo Park, CA, USA).

\section{Histology}

The testis tissue from transgenic mice (aged $2 \mathrm{mo}$ ) in Experiment 2 was collected and fixed in Bouin's solution overnight, embedded in paraffin for serial sectioning at 5-7 $\mu \mathrm{m}$. The sections were stained with hematoxylin and eosin (H.E., Sigma-Aldrich, USA) and viewed under the light microscope (Olympus, Japan).

\section{Bisulfite sequencing PCR}

The genomic DNA from the testis tissue of transgenic F1 mice (pre-founder transduced with lentivirus with promoter CMV or EF-1) was directly subjected to bisulfite conversion with EZ DNA Methylation Direct kit (Zymo Research, Orange, CA, USA) according to the manufacturer's protocol. The BSP specific primers (Table 2) were used for bisulfite-modified DNA amplification. After bisulfite conversion, the PCR products were cloned into a pGEM-T Easy Vector (NEB, England), and nine individual clones with different promoters were sequenced by $\mathrm{BIO} 5$ Institute, University of Arizona.

\section{Results}

To compare an effect of site at which the lentivirus was injected, recombinant lentiviral vectors (pCD513BCMV-MCS-EF1) containing an EF-1 promoter to drive eGFP expression were injected into the inter-tubular 
space of testis (group $\mathrm{A} / \mathrm{C}$ ) or seminiferous tubules (group B/D). At 5 or $6 \mathrm{wk}$ after injection, pre-founder mice were mated with wild type females of the same strain (1.5 to 2.0-month-old), as it needs around $35 \mathrm{~d}$ to fulfill the entire process of spermatogenesis in mice [20].

To test the eGFP transgene in pre-founder testis and F1 pups, eGFP specific primers and gapdh primers (as a loading control) were used for DNA amplification (Table 1). To our great surprise, overall $67.88 \%$ (131/ 193) of F1 pups were positive for eGFP transgene (Fig. 2d-e, Table 1 and Additional file 1: Table S1). Interestingly, there was no significant difference in F1 transgenic rate either between two injection sites or between two ages of pre-founders $(P>0.05)$. F2 generation was generated from either transgenic $\mathrm{F} 1$ animals mating each other or transgenic F1 mice mating with wild-type C57BL/J mice (Fig. 1). The eGFP gene can be identified from these two strategies in F2 pups with transgenic rate over $55.0 \%$, indicating the transgene could be heritable. The transmission rate was as high as $55.6 \%$ in F2 pups (Fig. 2, Table 1 and Additional file 1: Table S1). However, the transgene expression was not detectable under a fluorescence microscopy or via RT-PCR.

The above observations from Experiment 1 suggested that the transgene was silenced or its expression was undetectable. As there was no difference for transgenesis between two injection sites, in Experiment 2, lentivirus (pLentiV-H1-MCS-CMV) with CMV promoter driving eGFP was injected into the inter-tubular space of mouse testes. The pre-founder preparation and F1 generation were implemented as the protocol described as Experiment 1 (shown in Fig. 1). Total ten pups of F1 generation were obtained from two pre-founders.

DNA from the tail samples of the pups was extracted for PCR. Three samples from one litter displayed $e G F P$ positive bands (Fig. 3b). gapdh, a housekeeping gene, was served as a loading control. Under a fluorescence lamp, five of the ten pups showed noticeable green fluorescence. RT-PCR and Western Blot analysis further confirmed the expression of eGFP transgene in different tissues of the No.3 pup (Fig. 3e). A non-transgenic testis was as negative control (NC) (Fig. 3c and d). Three of seven F1 pups in one litter showed eGFP fluorescence (Fig. 3e), and two of three F1 pups in another litter showed eGFP fluorescence. After dissection, seminiferous tubule from an adult transgenic F1 generation showed eGFP fluorescence under fluorescence microscope (Fig. 3f). The cross section of testis tissue showed the complete spermatogenesis with spermatozoa (Fig. 3g, h). As CMV promoter may drive eGFP expression in both somatic Sertoli cells and germ cells within seminiferous tubules, to further confirm whether germ cells were indeed expressed eGFP transgene, immunohistochemistry was conducted using germ cell specific marker (VASA). As shown in Additional file 1: Figure S2, some eGFP green cells were expressed VASA, suggesting that eGFP transgene was expressed in germ cells and thus may passage to next generations.

To further elucidate whether the silence of GFP transgene was related with DNA methylation at the promoter region, which was used to drive the gene of interest, DNA methylation level in the EF-1 and CMV promoters were analyzed. DNA from the lentiviral-medicated F1 generation was subject to bisulfite convention. Specific primers for bisulfite sequencing PCR (BSP, Table 2) were used for amplifying DNA methylation in the region of EF1 or CMV promoter. DNA methylation in EF1 and CMV promoter were totally different, $87.8 \%$ vs. $45.5 \%$ (Fig. 4), suggesting that DNA from the pCD513B-CMV-MCS-EF1 lentivirus-mediated transgenic pups (Experiment 1) displayed much higher methylation level in the region of promoter for driving eGFP expression than that from pLentiV-H1-MCS-CMV lentivirus-mediated transgenic mice (Experiment 2). These data indicates that expression of eGFP in Experiment 1 was repressed by DNA methylation.

Table 1 Percentage of eGFP positive pups obtained from F1 and F2 generations in Experiment1

\begin{tabular}{|c|c|c|c|c|c|}
\hline \multirow{2}{*}{$\frac{\text { Genetarion }}{\text { F1 generation }}$} & \multicolumn{2}{|l|}{ Groups } & \multirow[t]{2}{*}{ No. litters } & \multirow[t]{2}{*}{ No. positive pups } & \multirow{2}{*}{$\begin{array}{l}\text { Percentage } \\
\text { Success rate, \% }\end{array}$} \\
\hline & Pre-founder age & Injection methods & & & \\
\hline & $7 d$ & IS group A & 31 & 21 & 67.8 \\
\hline & & ST group B & 60 & 40 & 66.7 \\
\hline & $28 d$ & IS group C & 45 & 30 & 66.7 \\
\hline & & ST group D & 57 & 40 & 70.2 \\
\hline & Grand total & & 193 & 131 & 67.88 \\
\hline \multirow[t]{4}{*}{ F2 generation } & Mating & & & & Transmission rate, \% \\
\hline & Transgenic $\times$ Wil & & 15 & 7 & 46.78 \\
\hline & Transgenic $\times$ Tra & & 21 & 13 & 61.90 \\
\hline & Grand total & & 36 & 20 & 55.56 \\
\hline
\end{tabular}

IS injection of lentivirus into inter-tubular spaces, $S T$ injection of lentivirus into seminiferous tubules 


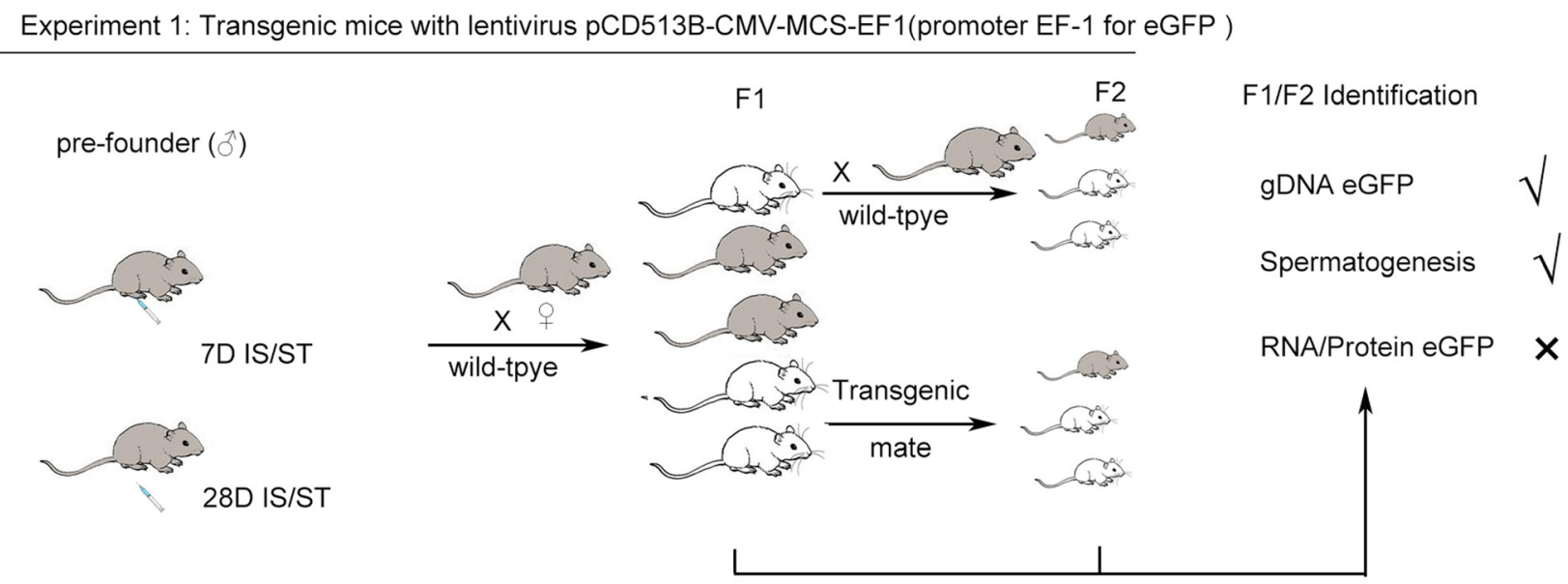

Expriment 2: Transgenic mice with lentivirus pLentiV-H1-MCS-CMV(promoter CMV for eGFP)

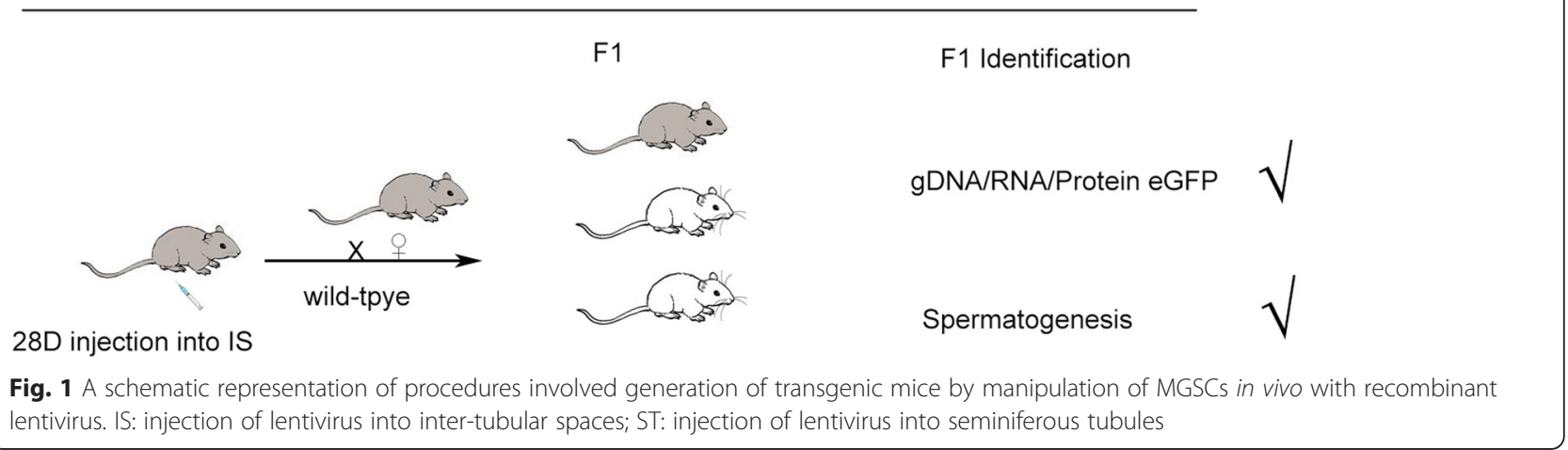

The above data provided an efficient, quick and effective protocol to generate transgenic mice via transduction of MGSCs with lentiviral vectors in vivo. This strategy did not compromise the fertility and development of descendants, resulting in transmission of the transgene through the male germ line.

\section{Discussion}

Recently, Sehgal et al. [16] reported that injection of lentiviral vector into mouse testes resulted in transduction of spermatogonia, and the pre-founder male mice could sire and produce transgenic pups. However, images of eGFP expressing pups were not shown in their article. Effects of injection techniques and age of on the efficiency of transgenesis were further conducted in the present study. Moreover, the differences in DNA methylation of two different promoters for driving transgene expression were analyzed. We found that transgenic mouse could produce in an injection site-and ageindependent manner through transduction of MGSCs in vivo using lentivirus vectors with specific promoters. Transgenic pups with eGFP fluorescence were generated using lentiviral vector in which eGFP expression cassette was under the control of $\mathrm{CMV}$ promoter.
Mammalian spermatozoa are produced in the seminiferous tubules which are compacted inside of testis. It is not known whether injection of lentivirus into the lumen of seminiferous tubules would lead to higher efficiency of transgenesis, compared to inter-seminiferous tubule injection. Therefore, first, we compared the strategies for injection of lentivirus. Similarly as the technique of germ cell transplantation, lentiviral based-vector was injected into seminiferous tubules via either rete testis or efferent ducts. Another method is that lentivirus was directly injected into inter-tubule space. We found that there was no significant difference for transgenesis between these two injection methods. Either microinjection into seminiferous tubules or direct injection into intertubular space transduced MGSCs with lentiviral vectors. Therefore, the simple and easily direct injection method was used in Experiment 2.

Second, gonocytes are the only type of germ cells in new-born mouse seminiferous tubules. By seven d after birth, gonocytes are migrated toward and attached to the basement membrane of seminiferous tubules and have differentiated to form type A spermatogonia among which undifferentiated spermatogonia are regarded as spermarogonial stem cells (SSCs), which were a sub- 


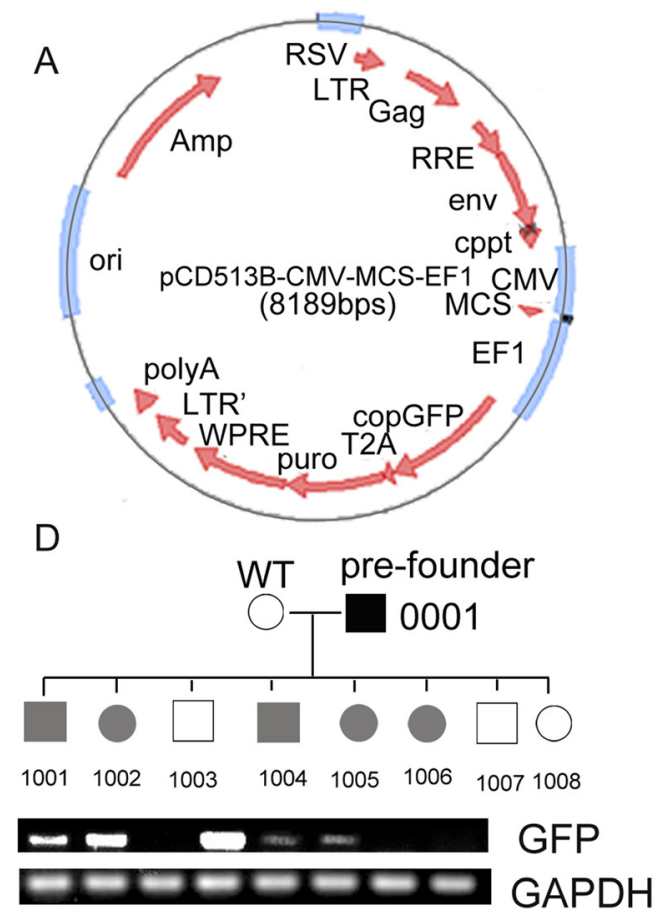

B
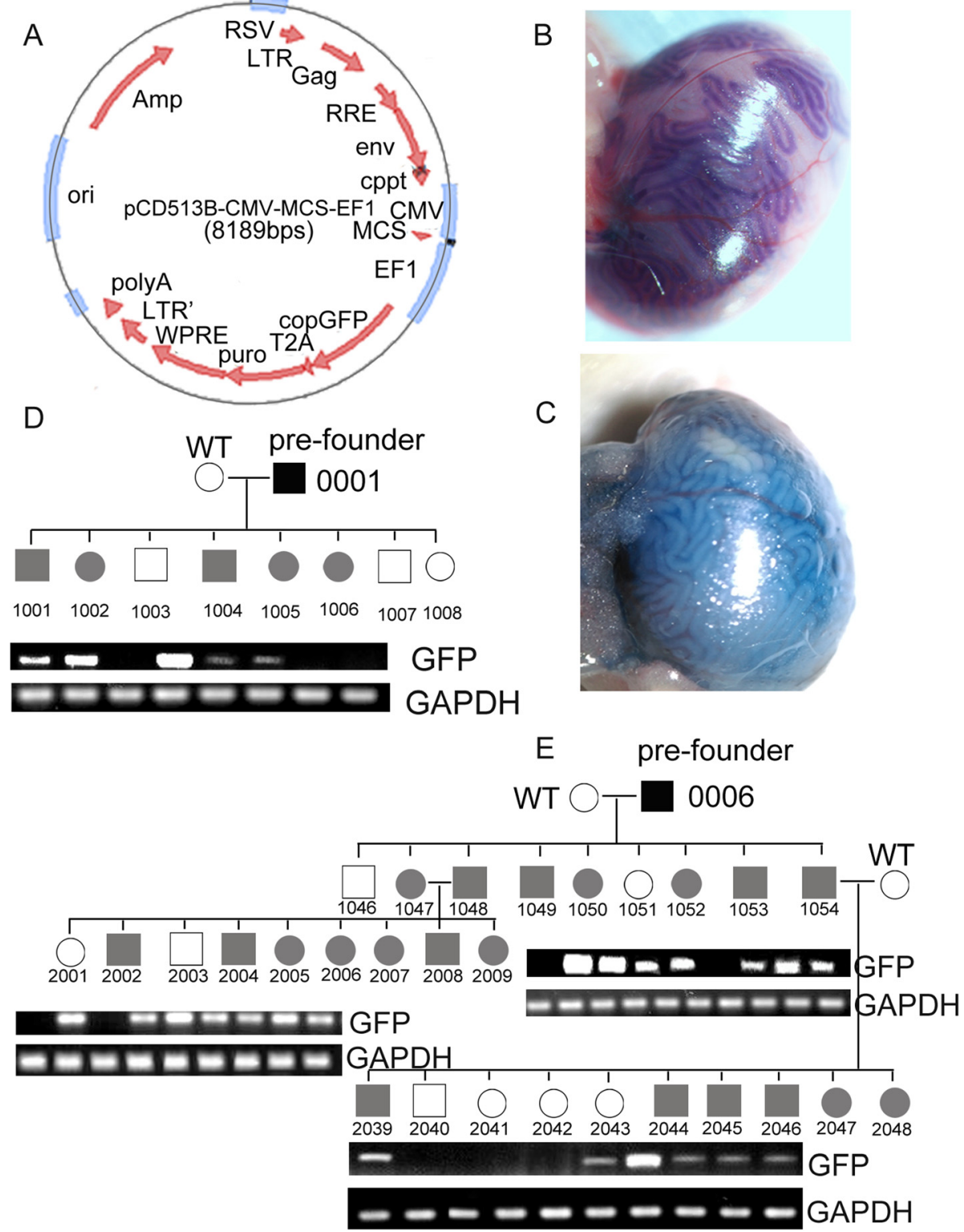

Fig. 2 Generation of transgenic mice via injection of lentivirus with EF1 promoter to drive eGFP expression in Experiment 1. a. Lentiviral vector used for generating transgenic mice. b-c. Recombinant lentiviruses injection into mouse testis via seminiferous tubules and inter-tubular spaces. d-e. Phenotype identification showing all germline transmission of the transgene such as pedigree analysis from pre-founder mice 006 (e) and 001 (d) with different ages or injection areas. gDNA amplification using the primers for eGFP transgene or GAPDH as shown

population of MGSCs [21]. By $28 \mathrm{~d}$ after birth, different types of germ cells are arranged in the epithelia of seminiferous tubules in which MGSCs are localized at the basement membrane. The rate of SSCs is higher in neonatal testis tissue than that in 28-day-old one. It is unclear whether infection of male germ cells in vivo at 7day-old age would higher efficiency than 28-day-old age. Therefore, effect of pre-founder on the transgenic efficiency was compared in our study. We found that efficiency of eGFP transgenesis between these two ages of pre-founders (Table 1). Therefore, these observations indicate that lentiviral vectors could successfully delivery genetic information to MGSCs in an injection site- and age-independent manner. As far as we know,it is the first time to present microinjection of virus into neonatal testis for production of transgenic animals.

Lentiviral vectors have been an attractive tool for transgensis because of their ability to transduce both dividing and quiescent cells and the high integrating efficiency [17, 22]. Meanwhile, male germline stem cells 


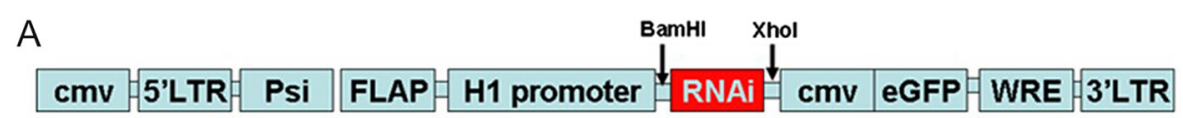

B

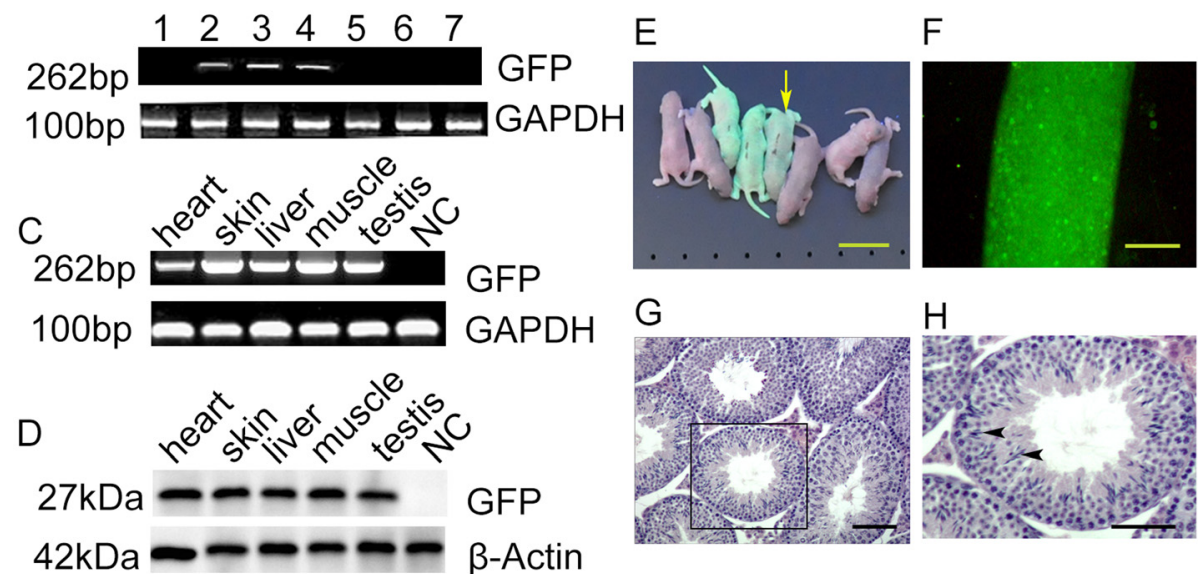

Fig. 3 Generation of transgenic mice via injection of lentivirus with CMV promoter to drive eGFP expression in Experiment 2. a. Lentiviral vector used for generating transgenic mice. b. gDNA amplification using the primers for eGFP transgene or GAPDH. Heart, skin, liver, muscle and testis tissue were collected from a pup indicated in (e), and the expression of eGFP transgene was detected via RT-PCR (c), Western Blot (d). E. eGFP expression in F1 pups was observed under a fluorescent lamp. F. Expression of eGFP in a seminiferous tubule. G. A cross section of testis tissue from a F1 transgenic mouse showed complete spermatogenesis. Bar $=100 \mu \mathrm{m}$ in $\mathrm{F}, \mathrm{G}$ and $\mathrm{H}, \mathrm{Bar}=1 \mathrm{~cm}$ in $\mathrm{E}$

(MGSCs) are perfect targets for transgenesis as they are the foundation of spermatogenesis [23]. Thus, a few studies have examined the utilization of lentivirual vectors as a tool to modify MGSCs genome in mice [24], rats [25-27] and pig [28, 29]. Nagano et al. [24] found that transplantation of the lentiviral vector-modified mouse MGSCs resulted in the establishment of spermatogenic colonies in all of the recipient mouse testis, but the authors did not examined the transmission of transgene in the subsequent generation. Hamra et al. [27] reported that $59 \%$ of the rat offspring were transgenic when the recipients of transplantation of lentiviral particle-mediated rat MGSCs were mated wild type females. Meanwhile, Ryu et al. [26] also found that rat

Table 2 Specific primers used in this study

\begin{tabular}{ll}
\hline Name of oligonucleotide & Sequence \\
\hline eGFP Forward & GACGTAAACGGCCACAAGTT \\
eGFP Reverse & TCTTGTAGTTGCCGTCGTCC \\
GAPDH Forward & CTCTCTGCTCCTCCCTGTTCC \\
GAPDH Reverse & CCAAATCCGTTCACACCGACC \\
BSP CMV Forward & TAAAAATAAATTATAAAAATTAAAATTT \\
BSP CMV Reverse & AATACCAAAACAAACTCCCATTAAC \\
BSP EF-1 Forward & TGTTTGTTTTTTTTTTAATTTA \\
BSP EF-1 Reverse & ACCCTACTTAAAAATACCCTCTCC \\
\hline
\end{tabular}

MGSCs were transduced efficiently with lentiviral particles, which led to the production of transgenic progeny following transplantation of the transduced MGSCs and mating of the recipient males. In a more recent study, Kanatsu-Shinohara et al. [25] observed that transduced rat MGSCs produced eGFP transgene-expressing spermatogenic cells when lentiviral vector-mediated cells were xeno-transplanted into the seminiferous tubules of immunodeficient mice, and microinsemination of these transgenic germ cells resulted in stably transmitted the eGFP transgene in the next generation. Lately, Zeng et al. [28] reported that lentivirus-based vector was effective in transducing pig MGSCs, resulting in the production of eGFP transgenic spermatozoa in recipient boars. Semen collected from these boars generated $21 \%$ transgenic IVF embryos, indicating that lentivirus-mediated MGSCs transduction results in transgene transmission in pigs as well. Thus combining of transplantation with transduction of MGSCs using lentivirus-based vectors can generate transgenic animals.

However, multiple factors contribute the overall low efficacy of generating transgenic animals by transducing MGSCs followed by transplantation. Preparation of recipient animals for transplantation is a big challenge. Inappropriate recipient preparation would lead to inefficient colonization of donor MGSCs and low fertility of the recipients. The amount of donor- 


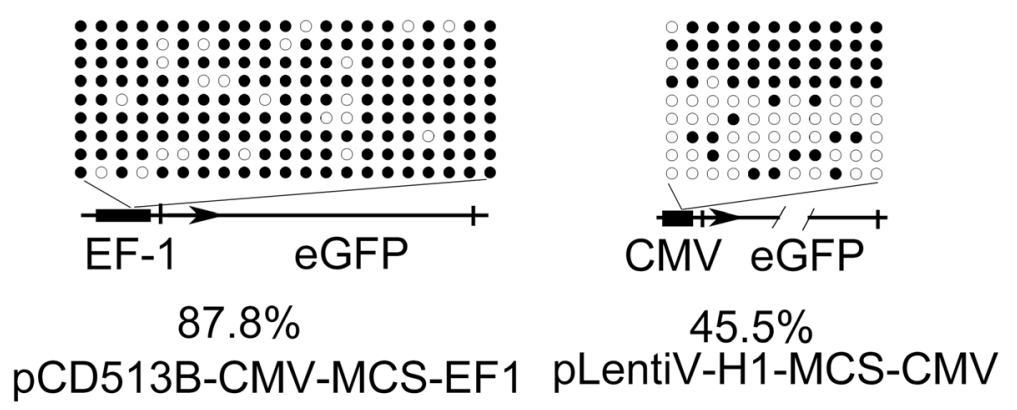

Fig. 4 Analysis of DNA methylation in the promoter of eGFP gene. The analysed position of CpG dinucleotide showed by a horizontal line. Open circles, unmethylated $\mathrm{CpG}$; closed circles, methylated CpG

derived spermatozoon production relative to endogenous production in the recipient host testis is another challenge, especially in rats and large animals. Therefore, alternative strategy for transgenesis is desirable.

The promoter affects the expression of transgene. A few studies showed that lentivirus particles could effectively transduce MGSCs in vitro and in vivo, and transgenic animals expressed GFP transgene under the control of EF-1 promoter [15, 30, 31]. Nagano et al. [24] reported that CMV promoter was not effective in lentiviral transduction and transgene expression in MGSCs. However, recently Liu et al. [32] and Usmani et al. [15] demonstrated that CMV promoter could drive transgene expression as well, which is in consistent with the findings obtained from the present study. As DNA methylation is generally associated with transcriptional silencing [33], we analyzed the methylation level in the region of promoters. The pups generated in Experiment 1 with pCD513B-CMV-MCS-EF1 expressed eGFP reporter gene in neither mRNA level nor protein level. Using BSP analysis, we found that DNA from the pups that were derived from transduction of pCD513B-CMVMCS-EF1 lentiviral vector displayed much higher level of DNA methylation in the promoter region than that DNA from pLentiV-H1-MCS-CMV, suggesting that the transgene was suppressed by DNA methylation in vivo. That is probably the main reason why the eGFP transgene was silenced or its expression was under detectable in Experiment 1. The DNA Methyl-transferase inhibitor should be explored in the research for driving the transgene expression with the specific promoter. Two promoters (EF1 and CMV) for driving eGFP expression were studied in this study. But experiments using testis tissue or germ cell specific promoter was not included in the present study. Lentiviral particles with spermatogonial stem cell (SSC) specific promoter would infect SSC solely in testis and probably lead to transgenic spermatozoa more efficiently, therefore, should be used in the future study. Therefore, a specific promoter of lentiviral vectors should be carefully considered for transgenic generation in vivo.

\section{Conclusions}

In conclusion, the strategy demonstrated here a stable, effective and reproductive way to produce transgenic mice with high success rate. Furthermore, this protocol could be applied to other animal species, especially livestock, leading to significant advancement of animal transgenesis in agricultural and biomedical fields.

\section{Additional file}

Additional file 1: More information about transgene in Experiment 1 and Experiment 2. (DOC $812 \mathrm{~kb}$ )

Competing interests

The authors declare that they no competing interests.

Authors' contributions

$J Z Q, H X X$ and $W X Z$ participated in the conception and designing and performing the research, analyzing the data, and writing the article. PFZ, $\mathrm{CHZ}, \mathrm{ZDZ}, \mathrm{RFQ}$ and YWQ participated in performing the research. All authors read and approved the final manuscript.

\section{Acknowledgements}

This study was supported in part by National Basic Research Program of China (973 program; 2013CB943103), the National Natural Science Foundation of China (Grant No. 31072029, No.31272439, No. C170104 and No. 31230048) and Ph. D. Programs Foundation of Ministry of Education of China (Grant No.20130204110017) for W. Zeng and W Dong, and J Qin received the scholarship from China Scholarship Council (CSC). We thank Dr. Wuzi Dong and Dr. Enqi Du for the generous gifts of recombinant lentiviral vectors. We thank Dr. Bin Wu (Arizona Center for Reproductive

Endocrinology and Infertility, Tucson, AZ 85712, USA) and Dr. Chuanying Pan (College of Animal Science and Technology, Northwest A \& F University,

Yangling, 712100, China) for critical reading the manuscript and comments.

Received: 29 July 2015 Accepted: 9 December 2015

Published online: 24 December 2015

References

1. Gordon JW, Scangos GA, Plotkin DJ, Barbosa JA, Ruddle FH. Genetic transformation of mouse embryos by microinjection of purified DNA. Proc Natl Acad Sci U S A. 1980;77(12):7380-4. 
2. Juliano $C E$, Lin $H$, Steele RE. Generation of transgenic Hydra by embryo microinjection. J Visual Exp. 2014;91:51888. doi:10.3791/51888. PubMed.

3. Yang $H$, Wang $H$, Jaenisch $R$. Generating genetically modified mice using CRISPR/Cas-mediated genome engineering. Nat Protoc. 2014;9(8):1956-68. doi:10.1038/nprot.2014.134.

4. Li W, Li X, Li T, Jiang MG, Wan H, Luo GZ, et al. Genetic modification and screening in rat using haploid embryonic stem cells. Cell Stem Cell. 2014; 14(3):404-14. doi:10.1016/j.stem.2013.11.016.

5. Feng X, Cao S, Wang H, Meng C, Li J, Jiang J, et al. Production of transgenic dairy goat expressing human alpha-lactalbumin by somatic cell nuclear transfer. Transgenic Res. 2015;24(1):73-85. doi:10.1007/s11248-014-9818-8.

6. Machaty Z, Bondioli KR, Ramsoondar JJ, Fodor WL. The use of nuclear transfer to produce transgenic pigs. Cloning Stem Cells. 2002;4(1):21-7. doi:10.1089/153623002753632011.

7. Garrels W, Talluri TR, Ziegler M, Most I, Forcato DO, Schmeer M, et al. Cytoplasmic injection of murine zygotes with Sleeping Beauty transposon plasmids and minicircles results in the efficient generation of germline transgenic mice. Biotechnol J. 2015. doi:10.1002/biot.201500218.

8. Wu HB, Wang YS, Zhang Y, Yang MQ, LV JX, Liu J, et al. TALE nickasemediated SP110 knockin endows cattle with increased resistance to tuberculosis. Proc Natl Acad Sci U S A. 2015;112(13):E1530-9. doi:10.1073/ pnas.1421587112.

9. Liu X, Wang YS, Guo WJ, Chang BH, Liu J, Guo ZK, et al. Zinc-finger nickase-mediated insertion of the lysostaphin gene into the beta-casein locus in cloned cows. Nat Commun. 2013;4. doi: 10.1038/Ncomms3565.

10. Zhang XH, Tee LY, Wang XG, Huang QS, Yang SH. Off-target Effects in CRISPR/Cas9-mediated Genome Engineering. Mol Ther Nucleic acids. 2015:4:e264. doi:10.1038/mtna.2015.37.

11. Zetsche B, Gootenberg JS, Abudayyeh OO, Slaymaker IM, Makarova KS, Essletzbichler P, et al. Cpf1 Is a Single RNA-Guided Endonuclease of a Class 2 CRISPR-Cas System. Cell. 2015;163(3):759-71. doi:10.1016/j.cell.2015.09.038.

12. Franca LR, Cardoso FM. Duration of spermatogenesis and sperm transit time through the epididymis in the Piau boar. Tissue \& Cell. 1998;30(5):573-82.

13. Dhup S, Majumdar SS. Transgenesis via permanent integration of genes in repopulating spermatogonial cells in vivo. Nat Methods. 2008;5(7):601-3. doi: 10.1038/nmeth.1225.

14. Honaramooz A, Megee S, Zeng W, Destrempes MM, Overton SA, Luo J, et al. Adeno-associated virus (AAV)-mediated transduction of male germ line stem cells results in transgene transmission after germ cell transplantation. FASEB J. 2008;22(2):374-82. doi:10.1096/fj.07-8935com.

15. Usmani A, Ganguli N, Sarkar H, Dhup S, Batta SR, Vimal M, et al. A nonsurgical approach for male germ cell mediated gene transmission through transgenesis. Sci Rep. 2013;3:3430. doi:10.1038/srep03430.

16. Sehgal L, Thorat R, Khapare N, Mukhopadhaya A, Sawant M, Dalal SN. Lentiviral mediated transgenesis by in vivo manipulation of spermatogonial stem cells. PLoS One. 2011;6(7):e21975. doi:10.1371/journal.pone.0021975.

17. Lattime EC, Gerson SL. Gene therapy of cancer: translational approaches from preclinical studies to clinical implementation: Academic Press. 2013.

18. An J, Zhang X, Qin J, Wan Y, Hu Y, Liu T, et al. The histone methyltransferase ESET is required for the survival of spermatogonial stem/ progenitor cells in mice. Cell Death Disease. 2014;5:e1196. doi:10.1038/cddis. 2014.171.

19. Chacon-Cortes D, Haupt LM, Lea RA, Griffiths LR. Comparison of genomic DNA extraction techniques from whole blood samples: a time, cost and quality evaluation study. Mol Biol Rep. 2012;39(5):5961-6. doi:10.1007/ s11033-011-1408-8.

20. Eddy EM. Male germ cell gene expression. Recent Prog Horm Res. 2002;57: 103-28.

21. Bellve AR, Cavicchia JC, Millette CF, O'Brien DA, Bhatnagar YM, Dym M. Spermatogenic cells of the prepuberal mouse. Isolation and morphological characterization. J Cell Biol. 1977;74(1):68-85

22. Frank JA, Erle DJ. Progress toward a systems biology approach to acute lung injury. Am J Physiol Lung Cell Mol Physiol. 2007;293(2):L290-1. doi:10. 1152/ajplung.00220.2007.

23. Aloisio GM, Nakada Y, Saatcioglu HD, Pena CG, Baker MD, Tarnawa ED, et al. PAX7 expression defines germline stem cells in the adult testis. J Clin Invest. 2014;124(9):3929-44. doi:10.1172/JCl75943.

24. Nagano M, Watson DJ, Ryu BY, Wolfe JH, Brinster RL. Lentiviral vector transduction of male germ line stem cells in mice. Febs Lett. 2002;524(1-3):111-5.

25. Kanatsu-Shinohara M, Kato M, Takehashi M, Morimoto H, Takashima S, Chuma S, et al. Production of transgenic rats via lentiviral transduction and xenogeneic transplantation of spermatogonial stem cells. Biol Reprod. 2008; 79(6):1121-8. doi:10.1095/biolreprod.108.071159.

26. Ryu BY, Orwig KE, Oatley JM, Lin CC, Chang LJ, Avarbock MR, et al. Efficient generation of transgenic rats through the male germline using lentiviral transduction and transplantation of spermatogonial stem cells. J Androl. 2007;28(2):353-60. doi:10.2164/jandrol.106.001511.

27. Hamra FK, Gatlin J, Chapman KM, Grellhesl DM, Garcia JV, Hammer RE, et al. Production of transgenic rats by lentiviral transduction of male germ-line stem cells. Proc Natl Acad Sci U S A. 2002;99(23):14931-6. doi:10.1073/pnas. 222561399.

28. Zeng W, Tang L, Bondareva A, Honaramooz A, Tanco V, Dores C, et al. Viral transduction of male germline stem cells results in transgene transmission after germ cell transplantation in pigs. Biol Reprod. 2013;88(1):27. doi:10.1095/biolreprod.112.104422.

29. Zhang Y, Xi Q, Ding J, Cai W, Meng F, Zhou J, et al. Production of transgenic pigs mediated by pseudotyped lentivirus and sperm. PLoS One. 2012;7(4):e35335. doi:10.1371/journal.pone.0035335.

30. Li X, Mao Z, Wu M, Xia J. Rescuing infertility of Pick1 knockout mice by generating testis-specific transgenic mice via testicular infection. Sci Rep. 2013;3:2842. doi:10.1038/srep02842.

31. Zhang M, Zhou H, Zheng C, Xiao J, Zuo E, Liu W, et al. The roles of testicular c-kit positive cells in de novo morphogenesis of testis. Sci Rep. 2014:4:5936. doi:10.1038/srep05936.

32. Liu C, Wang L, Li W, Zhang $X$, Tian $Y$, Zhang $N$, et al. Highly efficient generation of transgenic sheep by lentivirus accompanying the alteration of methylation status. PLoS One. 2013;8(1):e54614. doi:10.1371/journal.pone. 0054614.

33. Schubeler D. Function and information content of DNA methylation. Nature. 2015;517(7534):321-6. doi:10.1038/nature14192.

\section{Submit your next manuscript to BioMed Central and we will help you at every step:}

- We accept pre-submission inquiries

- Our selector tool helps you to find the most relevant journal

- We provide round the clock customer support

- Convenient online submission

- Thorough peer review

- Inclusion in PubMed and all major indexing services

- Maximum visibility for your research

Submit your manuscript at www.biomedcentral.com/submit
) Biomed Central 